\title{
Dissociated imageability, concreteness, and familiarity in lateralized word recognition
}

\author{
DAVID B. BOLES \\ University of Calgary, Calgary, Alberta, Canada
}

\begin{abstract}
According to Paivio's (1971) dual-coding theory, the representational memory of words is indexed by familiarity ratings, whereas associated imagery (one type of referential memory) is indexed by imageability and concreteness ratings. The theory predicts that word recognition near threshold will be influenced only by the former and not by the latter two attributes. However, previous empirical findings are unclear on this issue. Furthermore, the report of some studies that imageability and concreteness interact with the visual field of presentation pose a potential challenge to the theory. Here, five experiments present lateralized words whose semantic attributes are dissociated by design and by correlational analysis. In support of the theory, a metaanalysis shows that only familiarity affects overall recognition and that none of the attributes interacts with visual field. Yet statistical power to find the effects was high, and a general right-field recognition advantage supports the hemispheric validity of the findings. Implications for continuous (e.g., "cascade") models of information processing are discussed.
\end{abstract}

Following publication of Paivio's (1971) seminal work on the role of imagery in psychological processes, considerable interest has centered on the place of imagery in word perception (e.g., Bradshaw, Nettleton, \& Taylor, 1981; Day, 1979; Marcel \& Patterson, 1978; Richardson, 1976). Typically, "imageability," the rated capacity of a word to evoke imagery (Paivio, Yuille, \& Madigan, 1968), is treated as one attribute that may affect perceptual threshold, percent correct, or reaction time (RT) measures of word recognition. Other semantic word attributes often investigated are "concreteness," the degree to which a word refers to an object, material, or person, and "familiarity," the rated frequency of word usage or exposure.

In Paivio's (1971) framework, there are close correspondences between these dimensions and theoretical "representational" and "referential" meanings of words. Familiarity is taken as the major index of representational meaning, the availability of a verbal code for psy. chological processing. In constrast, imageability and concreteness are considered to be essentially the same dimension and to index one type of referential meaning, the association between word and image. In informationprocessing terms, it is representational meaning that is at a lower level and that determines threshold and nearthreshold recognition of words, whereas referential meaning is at a higher associational level and thus exerts little impact on recognition per se. By this account, familiarity but not imageability or concreteness should affect the recognition for words near threshold, since asso-

Reprint requests should be addressed to David B. Boles, Department of Psychology, University of Illinois at UrbanaChampaign, Champaign, Illinois 61820 . ciational influences can presumably influence processing only after recognition has occurred.

Nevertheless, at least three potential challenges to this viewpoint have appeared in recent years. One is that, although empirically imageability and concreteness are highly correlated (Gilhooly \& Hay, 1977; Paivio et al., 1968), logically speaking, these dimensions are separable. Indeed, Paivio et al. acknowledged the possibility of a dissociation by ratings: For example, "anger" is much higher in imageability than in concreteness, whereas the opposite is true for "antitoxin." Clearly, although a noun typically has strongly related values of "visualizability" and "thingness," these are not synonymous. An antitoxin is a thing (it is concrete) but is also hard to visualize (it has low imageability). Anger readily evokes imagery, and yet is not a concrete thing. This casts some doubt on the equation of imagery and concreteness as a single dimension.

The second potential challenge is an empirical one. Studies investigating the relationships of word norms to recognition have, on balance, yielded conflicting results. Although some have supported Paivio's position in finding essentially null effects of imageability (Kelly \& Orton, 1979; Paivio \& O'Neill, 1970; Richardson, 1976) or concreteness (Hines, 1976; Orenstein \& Meighan, 1976; Richardson, 1976; Shanon, 1979; Winnick \& Kresse1, 1965), others have reported beneficial effects of one (Day, 1979; Marcel \& Patterson, 1978; Schmuller \& Goodman, 1979) or the other (Borkowski, Spreen, \& Stutz, 1965; Ellis \& Shepherd, 1974; Elman, Takahashi, \& Tohsaku, 1981; Hatta, 1977; Jones \& Spreen, 1967; Riegel \& Riegel, 1961; Spreen, Borkowski, \& Benton, 1967), and significant detrimental effects of concreteness have even appeared (Day, 1977; Rubenstein, Garfield, \& Millikan, 1970). As for familiarity/frequency 
(the latter being the objective dimension presumably underlying subjective ratings of the former), here the literature is virtually unanimous in supporting a significant effect on word recognition (Bradshaw \& Gates, 1978; Caplan, Holmes, \& Marshall, 1974; Hines, 1976; Howes \& Solomon, 1951; McGinnies, Comer, \& Lacey, 1952; Paivio \& O’Neill, 1970; Richardson, 1976; Riegel \& Riegel, 1961; Rubenstein, Garfield, \& Millikan, 1970; Solomon \& Howes, 1951; Taylor, Rosenfeldt, \& Schulz, 1961; Winnick \& Kressel, 1965), the single exception nevertheless showing a trend in the predicted direction (Orenstein \& Meighan, 1976).

From the foregoing citations, it is apparent that support for the theory is equivocal. Although familiarity/ frequency unquestionably affects recognition, findings relative to imagery and concreteness are in conflict and, taken together, may even suggest beneficial roles of each, a conclusion that, if true, would compromise the theory.

It must be emphasized, however, that several previous studies have exerted inadequate control over the semantic dimensions. Only one study appears to have attempted the simultaneous dissociation of all three. Richardson (1976) used words varying orthogonally in imageability and concreteness, controlling familiarity by matching and correlational analysis. In accord with the theory, only familiarity exerted any effect. Nevertheless, this result is clouded by findings that concreteness (with imageability presumably covarying) beneficially affects word recognition when familiarity/frequency is controlled (Day, 1977; Ellis \& Shepherd, 1974; Hatta, 1977; Jones \& Spreen, 1967; Orenstein \& Meighan, 1976; Riegel \& Riegel, 1961). Adding to the confusion once again are studies in which familiarity/frequency was controlled and that reported no effect of concreteness (Hines, 1976; Shanon, 1979; Winnick \& Kressel, 1965) or a detrimental effect (Rubenstein et al., 1970).

The third challenge to Paivio's position relating word recognition and imagery comes from literature examining hemispheric differences in word recognition. This literature is an outgrowth of more general investigations in which words are presented to the left and right visual fields, or to the left and right ears, with the right side of space (visual field or ear) typically showing higher accuracy in near-threshold recognition and faster RT in lexical decision (e.g., Bryden \& Allard, 1978; Leiber, 1976; Mackavey, Curcio, \& Rosen, 1975). The superiority is attributed to more efficient language processing in the left hemisphere, with hemifield asymmetry due to less efficient processing of words presented to the right hemisphere. Recently, it has been found that the effect is largest given simultaneous stimulation of both hemispheres, implicating some type of hemispheric interaction in the determination of asymmetry (Boles, 1983).

Beyond these general observations, however, a number of studies have explored concreteness, imageability, and, to a much lesser extent, familiarity as variables modifying asymmetry. With regard to concreteness, the right-hemifield advantage for word recognition has been reported to be attenuated or even eliminated in certain studies when concreteness is high (Day, 1977; Ellis \& Shepherd, 1974; Elman et al., 1981; Hines, 1976; McFarland, McFarland, Bain, \& Ashton, 1978; Sugishita, 1978 ), although equally prominent are studies in which concreteness failed to interact with the hemifield factor (Borkowski et al., 1965; Bradshaw et al., 1981; Hatta, 1977; Jones \& Spreen, 1967; Marcel \& Patterson, 1978; Orenstein \& Meighan, 1976; Saffran, Bogyo, Schwartz, $\&$ Marin, 1980; Shanon, 1979). Furthermore, the successful replications often have peculiarities, including a possible conflict between an attenuated, yet still present, right-field advantage for concrete words in some studies (Hines, 1976; Ellis \& Shepherd, 1974) and a fully eliminated or even reversed (left-field) superiority in others (Day, 1979; Elman et al., 1981; McFarland et al., 1978). Hines (1976) obtained the interaction only for highfrequency and not low-frequency words. Elman et al. (1981) had subjects recognize a word and a digit on each trial, but apparently took vocal RTs to the digit rather than to the word. Sugishita (1978) reported a single split-brain subject. McFarland et al. (1978) used an old/ new discrimination, probably transforming the task's focus from perception to memory. Finally, the visual study by Ellis and Shepherd (1974) was weakened by the straightforward replication of Orenstein and Meighan (1976), who did not obtain the same results.

The picture is also mixed when imageability is considered. Day (1979) varied this dimension and obtained results analogous to the "successful" concreteness studies: a reduced (in this instance, eliminated) right-visual-field asymmetry for highly imageable words. A similar robust effect was reported by Marcel and Patterson (1978), although methodological and statistical details are insufficient to permit evaluation. In contrast, most experiments have failed to support a significant role for imageability (Bradshaw et al., 1981; Haynes \& Moore, 1981; Kelly \& Orton, 1979, as interpreted by Lambert \& Beaumont, 1981; Saffran et al., 1980; Schmuller \& Goodman, 1979).

The potential challenge of these results to Paivio's theory (although its realization is arguable) is that, if concreteness and/or imageability modify hemifield asymmetry, this implies that "referential meaning" in Paivio's sense does influence near-threshold recognition. The imagery value of an item, in other words, would be in some way responsible for differential recognition of the item by the two hemispheres. This would contradict the distinction between representational and referential (associational) memories in much the same way as would a generalized effect of imageability or concreteness, as discussed above.

However, as with the putative general effect, one limitation of the asymmetry literature is that little effort has been made to dissociate all three word attributes. Closest were the studies of Marcel and Patterson (1978), with 
concreteness and imageability varying orthogonally in the first experiment, and with imageability varying while concreteness and familiarity were controlled in the second. Unfortunately, the details are too vague to allow an evaluation of the results.

From this review it should be clear that the role of word attributes in determining overall recognition and hemifield differences is uncertain. Familiarity/frequency consistently affects overall recognition, but the influences of concreteness and imageability are at best unstable. In the hemispheric literature, no attribute can yet be said to produce a consistent modifying influence on hemifield asymmetry. Largely missing from both literatures are dissociations of all three attributes, which are perhaps the only means available of separating any intercorrelated influences.

It should be noted that, in conducting this review, an effort was made to determine whether particular design characteristics were correlated to the outcomes of the studies. Dichotomous variables examined included: the nature of the dependent measure (accuracy vs. RT); the language of the words employed (English vs. nonEnglish); whether or not familiarity/frequency was controlled; and modality (visual vs. auditory). In the visual modality specifically, variables examined included: the presentation style (for lateralized presentations, unilateral vs. bilateral presentations); apparatus (tachistoscope vs. slide projector, and also slide projector vs. CRT); orientation of the words (horizontal vs. vertical); and whether or not a patterned postmask was used. Continuous variables included the numbers of subjects and trials (and their product) and, in the visual modality, the duration of the stimuli. Correlations were calculated between each variable and the dichotomized outcomes of the studies: both for the main effect of imageability/ concreteness (if either significantly improved performance, it was considered a "successful" replication), and for the interaction with visual field (if either high imageability or concreteness significantly shifted asymmetry away from a right-field advantage, it was considered "successful"). Of over 20 correlations thus examined, only 1 was significant, the correlation between the number of subjects and whether or not the interaction was successfully produced $(r=-.50, p<.05)$. Because of the large number of statistical comparisons made, this may represent Type I error, but if it is taken seriously, it gives little support for the veridicality of the interaction: The negative correlation indicates that the "successful" replications were the studies with the smallest numbers of subjects. In any event, the overall effort indicates that there are no apparent design characteristics that account for the mixed state of the previous literature.

Finally, it should be emphasized that the rationale for placing these results within the framework of Paivio's theory is that the theory provides a unique view of the relationship between a word and the imagery it evokes. That relationship is of clear importance in understanding the coordination of memory codes (see Posner \&
McLeod, 1982), and the contribution of Paivio's theory is that it explicitly hypothesizes a linkage between word and image. Furthermore, the linkage is proposed to be at a "higher," more "associational" level than that at which verbal and imagery codes are themselves represented. The theory even involves hemispheric differences, since the codes were viewed by Paivio (1971) as being not only functionally dissociated, but anatomically dissociated as well, representing left- and right-hemisphere lateralization, respectively. For these reasons, the theory has been adopted here as a proper framework. This is not to say, however, that other aspects of the theory have not been questioned; more discussion of this issue will appear later.

In the present experiments, further evidence bearing on the model is adduced in a near-threshold visualfield paradigm, employing word sets varying orthogonally in concreteness and imageability but with familiarity allowed to covary. The rationale is that the observed high correlation of concreteness and imageability requires special attention to be given to their dissociation, whereas the modest correlations of familiarity to both (Gilhooly \& Hay, 1977) makes unnecessary any special effort to isolate its effects. As will be seen, partial correlation is adequate assessment in this instance, producing a dissociation of the three attributes.

\section{METHOD}

Five experiments were conducted, with minor alterations in method. Because all experiments produced similar results (within the constraints of presumed random variation), all five will be treated together by metaanalysis using the "Stouffer method" (Rosenthal, 1978). The following are brief descriptions of the methods used in each experiment.

\section{Experiment 1}

Four lists, each composed of eight five-letter words, were constructed using the ratings of Gilhooly and Hay (1977): (1) low concreteness (mean $=4.49, \mathrm{SD}=.36$ ) and low imageability (mean $=3.87, \mathrm{SD}=.24) ;(2)$ low concreteness (mean $=$ $4.46, \mathrm{SD}=.45$ ) and high imageability (mean $=5.56, \mathrm{SD}=.46$ ); (3) high concreteness (mean $=5.59, \mathrm{SD}=.45$ ) and low imageability $($ mean $=3.84, \mathrm{SD}=.59)$; and $(4)$ high concreteness $($ mean $=5.64, \mathrm{SD}=.31)$ and high imageability $($ mean $=5.49$, $\mathrm{SD}=.34$ ). Each word was typed horizontally (extending $1.2 \mathrm{deg}$ ) in capital letters on two white cards, positioned either in the left or right visual field (with the near end $0.8 \mathrm{deg}$ from fixation). A single random digit was also typed at the fixation point on each card, since it had been found that displays with a bilateral aspect (in this case, the digit overlaps the vertical midline) yield larger asymmetry than do unilateral displays (Boles, 1983). Cards were exposed at maximum intensity in a twochannel tachistoscope for $100 \mathrm{msec}$, following by about $1 \mathrm{sec}$ the spoken warning signal "ready." In the "ready" interval, the subjects fixated a small gap in a vertical line and subsequently reported both digit and word. The deck of 64 cards was run through twice, each time ordered randomly; six male and two female right-handed subjects participated. As in all of the present experiments, these subjects had to identify correctly both the digit and the word to be scored as correct.

\section{Experiment 2}

Four lists of five words each were constructed from the same ratings source: $(1)$ low concreteness $($ mean $=3.06, \mathrm{SD}=.19$ ) and 
average imageability $($ mean $=4.13, \mathrm{SD}=.34) ;(2)$ high concreteness (mean $=5.91, \mathrm{SD}=.25)$ and average imageability (mean $=$ $4.03, \mathrm{SD}=.27) ;(3)$ average concreteness (mean $=4.04, \mathrm{SD}=.43$ ) and low imageability (mean $=2.51, \mathrm{SD}=.42)$; and (4) average concreteness (mean $=4.03, \mathrm{SD}=.31$ ) and high imageability (mean $=5.57, \mathrm{SD}=.37$ ). Each word was constructed vertically (subtending $4.2 \mathrm{deg}$ ) from bold press-on capital letters, and appeared for $90 \mathrm{msec}$ in one visual field or the other $(1.5 \mathrm{deg}$ from fixation) with a single random digit at fixation. The deck of 40 cards was given five times (in different random orders) to each of 4 male and 12 female right-handers. Otherwise, the procedure was as in Experiment 1. The purpose of the experiment was to increase the ratings differences between word sets by matching sets on one dimension while varying the other. Vertical word presentation also minimized possible scanning and position artifacts. Variation in the stimulus duration from Experiment 1 reflected an attempt to produce a middle level of accuracy through initial pilot work.

\section{Experiment 3}

This study was similar to Experiment 2, except that fourletter words from Paivio et al. (1968) were used, with familiarity ratings coming from unpublished norms by Paivio (Note 1 ). The word sets were: $(1)$ low concreteness (mean $=2.65, \mathrm{SD}=1.25$ ) and average imageability (mean $=4.34, \mathrm{SD}=1.02$; $(2)$ high concreteness (mean $=5.39, \mathrm{SD}=1.06)$ and average imageability $($ mean $=4.27, \mathrm{SD}=.98 ;(3)$ average concreteness $($ mean $=4.77$, $\mathrm{SD}=.88$ ) and low imageability (mean $=3.16, \mathrm{SD}=.88$ ); and (4) average concreteness (mean $=4.69, \mathrm{SD}=1.83$ ) and high imageability (mean $=5.52, \mathrm{SD}=1.53$ ). The words were vertical, subtended $3.2 \mathrm{deg}$, and were presented for $75 \mathrm{msec}$. Five male and three female subjects participated, and the other procedural details were the same as in Experiment 2. The purpose of the study was to determine whether word length is an important variable in this type of research.

\section{Experiment 4}

Also similar to Experiment 2, this study employed word sets with the following characteristics: (1) low concreteness (mean = $4.04, \mathrm{SD}=.32$ ) and high imageability (mean $=5.70, \mathrm{SD}=.24)$; (2) high concreteness (mean $=6.48, \mathrm{SD}=.04$ ) and high imageability (mean $=5.76, \mathrm{SD}=.23)$; (3) average concreteness $($ mean $=$ $4.92, \mathrm{SD}=.36)$ and low imageability (mean $=3.20, \mathrm{SD}=.20)$; (4) average concreteness (mean $=4.93, \mathrm{SD}=.43$ ) and high imageability (mean $=5.98, \mathrm{SD}=.52$ ). Five males and seven females participated. The method was otherwise identical to that of Experiment 2. The purpose was to extend the "ceiling" for both concreteness and imageability by matching the other variable at a higher level, in the expectation that a more sensitive test of their effects would result.

\section{Experiment 5}

This experiment used a somewhat different scheme of wordset construction, employing the same ratings source as in Experiment 2 to produce two sets each of 10 five-letter words. The word sets were: $(1)$ high concreteness $($ mean $=5.86, \mathrm{SD}=.26$ ) and average imageability (mean $=4.49, \mathrm{SD}=.49$ ); and $(2)$ average concreteness (mean $=4.67, \mathrm{SD}=.62$ ) and high imageability (mean $=5.53, \mathrm{SD}=.27$ ). In most respects, the procedure was similar to that in Experiment 2, except that presentation of these sets could be either mixed or blocked. Each of the subjects (four males and eight females) received two blocks of 20 Set 1 trials, two blocks of 20 Set 2 trials, and two blocks of 40 intermixed Set 1 and Set 2 trials, with block order balanced across subjects. The purpose was to determine whether blocked and mixed conditions would produce contrasting results. The logic of using only two word sets was that, if either concreteness or imageability (but not both) affect asymmetry, one of the word sets would produce a reduced visual-field difference.

\section{RESULTS}

Metaanalyses are reported in lieu of individual analyses for each experiment.

\section{Word Attributes and Overall Recognition}

Table 1 presents correlations between each dimension and overall recognition (percent correct) of the words with the effects of the other two attributes partialed out (Ferguson, 1981, p. 465), in each of the five experiments. Average correlations $\left(r^{\prime}\right)$ were calculated using the r-to-z transformation (Hays, 1973, p. 662). The sig. nificance of $r^{\prime}$ was assessed by (1) determining the onetailed $\mathrm{p}$ value associated with each individual correlation, (2) determining each corresponding $z$ score (zp), and (3) calculating an overall $z$ score $\left(z^{\prime}\right)$ as the sum of $z p$ divided by the square root of $\mathrm{N}$, with $\mathrm{N}=5$ (Rosenthal, 1978).

As Table 1 shows, concreteness and imageability bore little relationship to overall recognition $\left(r^{\prime}=+.12\right.$ and -.03 , respectively). Familiarity, on the other hand, showed a significantly positive relationship, with more familiar words being better recognized $\left(\mathrm{r}^{\prime}=+.33\right.$, onetailed $p=.0008$ ). If the other attributes are not partialed out, there is little change in the results, the correlations then being $+.05,+.07$, and +.38 , respectively.

Although these results give little support to the notion that imageability or concreteness affect word recognition, examination of Table 1 shows that in one of the five experiments (Experiment 4), there was a significant correlation between recognition and concreteness $(r=+.52)$. For three reasons, it is believed that this cor-

Table 1

Partial Correlations of Word Attributes to Overall Recognition

\begin{tabular}{|c|c|c|c|c|c|c|c|c|c|}
\hline \multirow[b]{2}{*}{ Experiment } & \multicolumn{3}{|c|}{ Concreteness } & \multicolumn{3}{|c|}{ Imageability } & \multicolumn{3}{|c|}{ Familiarity } \\
\hline & $\mathbf{r}$ & $\mathrm{p}$ & $\mathrm{Zp}$ & $\mathbf{r}$ & $\mathrm{p}$ & $\mathrm{Zp}$ & $\mathbf{r}$ & p & $\mathrm{Zp}$ \\
\hline 1 & .10 & .30 & .52 & .04 & .42 & .21 & .49 & .004 & 2.65 \\
\hline 2 & .01 & .48 & .04 & .00 & .50 & .00 & -.16 & .74 & -.63 \\
\hline 3 & -.05 & .58 & -.20 & -.06 & .59 & -.24 & .56 & .008 & 2.41 \\
\hline 4 & .52 & .01 & 2.18 & -.19 & .77 & -.75 & .04 & .44 & .16 \\
\hline 5 & -.01 & .52 & -.04 & .08 & .38 & .31 & .57 & .007 & 2.46 \\
\hline
\end{tabular}

Note-Concreteness: $r^{\prime}=+.12, z^{\prime}=+1.12, p^{\prime}=.13 ;$ imageability: $r^{\prime}=-.03, z^{\prime}=-.21, p^{\prime}=.58 ;$ familiarity: $r^{\prime}=+.33, z^{\prime}=+3.15$, $p^{\prime}=.0008$. 
relation is not veridical. First, examination of the separate conditions of the experiment showed that the effect was virtually entirely due to depressed performance in the low-concreteness/high-imageability condition (33.0\% correct) compared with the averageconcreteness/low-imageability $\quad(64.5 \%)$, averageconcreteness/high-imageability $(66.7 \%)$, and highconcreteness/high-imageability $(67.2 \%)$ conditions. In other words, the effect of concreteness was apparent in the low-to-average range, not in the average-to-high range, and yet the design feature that distinguishes this experiment from the rest was an extension of the "ceilings" on rated concreteness and imageability, None of the other experiments, of course, showed an analogous effect over similar portions of the concreteness range (note particularly Experiments 2 and 3), so there is no reason to isolate this result and interpret it independently of the others. Second, a test of homogeneity of the concreteness results in Table 1 (Rosenthal \& Rubin, 1979) shows that they easily pass $\left[\chi^{2}(4)=3.82\right]$, so again there is no reason to interpret Experiment 4 in isolation. Finally, it is noteworthy that a similar result was not seen for imageability $(r=-.19)$, so it was not the case that these theoretically related (although experimentally dissociated) dimensions produced congruent results. The implication of these considerations when taken with the metaanalysis is that the concreteness effect in Experiment 4 probably represents Type I error, not a surprising outcome considering the multiple statistical comparisons represented in Table 1.

\section{Word Attributes and Visual-Field Asymmetry}

As an initial step in the analysis of word attributes' effects on asymmetry, overall asymmetry was assessed as a minimal test of the hemispheric validity of the experiments. Table 2 presents the visual-field effects obtained in each experiment, with an overall probability calculated by $z^{\prime}$ as above. Across the studies, the right visual field showed a highly significant superiority over the left field ( $55.3 \%$ vs. $\left.49.9 \%, p=9 \times 10^{-8}\right)$, validating the paradigm employed.

Next, Tables 3 through 5 present the respective influences of concreteness, imageability, and familiarity on visual-field asymmetry. For the first two, these influences were assessed as the arithmetic interaction of

Table 2

Visual Field Asymmetry

\begin{tabular}{clcccc}
\hline \multirow{2}{*}{$\begin{array}{c}\text { Experi- } \\
\text { ment }\end{array}$} & \multicolumn{2}{l}{ Percent Correct } & & \\
\cline { 2 - 3 } & RVF & LVF & Difference & p & Zp* \\
\hline 1 & 68.0 & 58.4 & 9.6 & .02 & 1.96 \\
2 & 51.1 & 45.2 & 5.9 & .00008 & 4.13 \\
3 & 58.0 & 54.3 & 3.7 & .002 & 2.88 \\
4 & 58.5 & 57.2 & 1.3 & .22 & .78 \\
5 & 40.8 & 34.2 & 6.6 & .004 & 2.64 \\
Mean & 55.3 & 49.9 & 5.4 & & \\
\hline
\end{tabular}

$*_{z^{\prime}}=5.54, p^{\prime}=9 \times 10^{-8}$ visual field (left vs. right) $\mathrm{x}$ value (high vs. low), since each experiment was factorially designed with respect to these attributes. For familiarity, however, the assessment was made by correlating asymmetry (right field correct minus left field correct) to value across words, since this attribute was not factorially varied.

Table 3 shows that, if anything, high concreteness increased visual-field asymmetry $(p=.10$, two-tailed), in contrast with the decrease reported by several studies reviewed in the introduction. Imageability and familiarity, on the other hand, had no discernible effects, as shown in Tables 4 and 5 .

To answer the question of whether the experiments achieved sufficient precision to detect influences of concreteness and imageability on asymmetry, power analyses were conducted by treating the difference scores of Tables 3 and 4 as samples of $\mathrm{N}=5$ and using the statistic and table supplied by Dixon and Massey (1969, Table A$12 \mathrm{~b}$ ). Necessary to these calculations was an estimation of the effect sizes that should have been obtained had the effects in fact been present. Since, of the seven previous studies reporting significant influences, five had found a right-field advantage for low-value words and either a nonsignificant left-field advantage or no asymmetry for high-value words (Day, 1977, 1979; Elman et al., 1981; Marcel \& Patterson, 1978; McFarland et al., 1978), the estimate was such that (1) the expected rightfield advantage for low-value words was set at the size of the visual-field main effect $(+5.4 \%)$ and $(2)$ the expected asymmetry for low-value words was set at zero. These are conservative estimates, since they represent a visual field $x$ value interaction of $+5.4 \%$, whereas the two excluded studies (Ellis \& Shepherd, 1974; Hines, 1976) showed interactions of $+17 \%$ and $+9 \%$, respectively. It was found that, under these assumptions and an alpha of .05 (one-tailed), there was .85 power to detect an interaction of visual field with concreteness value, and .99 power to detect an interaction with imageability.

Consideration was also given to the possibility that treating each attribute separately somehow masked any influence of the attributes on asymmetry. Across the five experiments, eight words were identified that were high in all three attributes: concreteness (mean $=6.17$, $\mathrm{SD}=.30)$, imageability $($ mean $=5.98, \mathrm{SD}=.60)$, and familiarity (mean $=5.55, \mathrm{SD}=.75$ ). Nevertheless, the mean right-visual-field asymmetry across the eight words

Table 3

Ef fect of Concreteness Value on Asymmetry

\begin{tabular}{ccrrrr}
\hline \multirow{2}{*}{$\begin{array}{c}\text { Experi- } \\
\text { ment }\end{array}$} & \multicolumn{2}{c}{ Concreteness Value } & & & \\
\cline { 2 - 3 } & Low & High & Difference & p & Z ${ }^{*}$ \\
\hline 1 & 8.2 & 10.9 & -2.7 & .85 & -1.03 \\
2 & 6.8 & 5.0 & 1.8 & .35 & .39 \\
3 & 0.5 & 7.0 & -6.5 & .98 & -2.07 \\
4 & 1.3 & 7.0 & -5.7 & .87 & -1.14 \\
5 & 6.9 & 6.5 & 0.4 & .44 & .16 \\
Mean & 4.7 & 7.3 & -2.5 & &
\end{tabular}

${ }^{*} z^{\prime}=-1.65, p^{\prime}=.9 .5$. 
Table 4

Effect of Imageability Value on Asymmetry

\begin{tabular}{crrrrr} 
& \multicolumn{4}{l}{ Percent Visual Field Difference } \\
\cline { 2 - 4 } Experi- & \multicolumn{2}{l}{ Imageability Value } & & & \\
\cline { 2 - 3 } ment & Low & High & Difference & $\mathrm{p}$ & Z ${ }^{*}$ \\
\hline 1 & 10.6 & 8.6 & 2.0 & .38 & .30 \\
2 & 7.0 & 4.8 & 2.2 & .19 & .88 \\
3 & 1.5 & 5.0 & -3.5 & .79 & -.82 \\
4 & -1.0 & -2.0 & 1.0 & .39 & .29 \\
5 & 6.5 & 6.9 & -0.4 & .56 & -.16 \\
Mean & 4.9 & 4.7 & 0.3 & & \\
\hline
\end{tabular}

$*_{z^{\prime}}^{\prime}=.22, p^{\prime}=.41$.

Table 5

Correlation of Familiarity Value to Asymmetry

\begin{tabular}{crrr}
\hline Experiment & \multicolumn{1}{c}{$\mathrm{r}^{*}$} & $\mathrm{p}$ & \multicolumn{1}{c}{$\mathrm{Zp}^{* *}$} \\
\hline 1 & -.33 & .03 & 1.83 \\
2 & -.26 & .14 & 1.10 \\
3 & .30 & .90 & -1.28 \\
4 & .34 & .92 & -1.44 \\
5 & -.21 & .19 & .89 \\
\hline
\end{tabular}

$*^{\prime}=-.03 . \quad * *_{z}^{\prime}=.49, p^{\prime}=.31$.

was equivalent to that for the entire word set, and was quite significant $[+7.4 \% ; t(7)=3.88, p<.01]$.

Finally, it might be noted that $I$ have preferred to leave the visual-field data in raw form (percent correct) rather than transforming them to any of a number of indexes of laterality that are reputedly independent of the overall level of performance (Bryden, 1982; Colbourn, 1978; Marshall, Caplan, \& Holmes, 1975). There are two motivations for this. First, since the results are left in a more natural form, they are somewhat easier to grasp than abstract indexes. Second, transforming the data makes the strong and potentially unwarranted assumption that asymmetry should never covary with accuracy (Birkett, 1977). An example will serve to demonstrate the possibly misleading nature of the assumption. Suppose that, in the present case, highly imageable words had been found to be more easily recognized than others, and had resulted in a reduced right-field advantage due to the ability of the right hemisphere to recognize these words. Under certain conditions, notably those in which low-imageable words are recognized at middle levels of accuracy and high-imageable words are recognized at higher levels, transformation using the proposed indexes could result in apparently equivalent asymmetry for the two sets of words. (Without belaboring the issue, it can be said that the transformations "correct" for ceiling effects by progressively inflating the asymmetry measure as accuracy approaches the ceiling.) In contrast, if lowimageable words are recognized with low accuracy, and high-imageable words are recognized with middle accuracy, transformation could produce a very large apparent difference in asymmetry. (Similarly, the transfor- mations "correct" for floor effects in the same progressive manner.) In lieu of this potentially misleading procedure, my own approach has been to test first for correlation between accuracy and asymmetry (right field minus left field) within conditions, and then if a correlation is found to apply a suitable transformation (e.g., Boles, Rogers, \& Wymer, 1982). This reduces the chance of erroneously scaling out a real difference in asymmetry between conditions. In the present experiments, all but 1 (of about 20) of these correlations were nonsignificant, so the results were left in raw form. Furthermore, attempts to rescale the data in the one significant condition were unsuccessful: Regardless of whether the lambda (Bryden, 1982), the phi (Colbourn, 1978), or the laterality coefficient sometimes called " $\mathrm{f}$ " (Marshall et al., 1975) was used, the correlations of the transformed indexes to accuracy actually increased slightly compared with that between the visual-field difference (in percent correct) and accuracy.

\section{DISCUSSION}

The major findings of the five experiments are that a robust right-visual-field advantage was obtained simultaneously with an influence of familiarity on overall word recognition. In contrast, little evidence was found that concreteness or imageability influences either asymmetry or overall performance.

These results support Paivio's (1971) distinction between "representational" and "referential" memories as applied to the effect of imagery on word recognition. Within this framework, familiarity is taken as indexing the strength of representational memory, accounting for its influence on near-threshold recognition. Referential (associative) memory, however, is posited to have no effect on recognition (essentially, associations are proposed to affect performance only after a stimulus has been recognized), and thus the indexes of concreteness and imageability show no relationship to word recognition. In these respects, the results of the experiments are in accord with theory and concur with the results of the previous study by Richardson (1976), apparently the only other published work that has attempted the simultaneous dissociation of all three word attributes. Furthermore, since a more general review of the literature largely confirms these findings (only familiarity/ frequency affects threshold and near-threshold recognition with any consistency, as shown in the introduction), the conclusion is drawn that no challenge to Paivio's theory is in fact posed by putative influences of concreteness or imageability on overall recognition.

Additionally, the potential challenge coming from literature claiming that concreteness or imageability interacts with the visual-field factor is weakened by the failure to demonstrate congruent effects in these experiments. Only an overall right-field advantage was obtained. Since, as noted in the introduction, the previous literature is in conflict on word-attribute effects, and 
peculiarities exist in most of the studies claiming effects, it seems reasonable to conclude that here, too, the representational-referential distinction remains intact. This is particularly defensible given the high statistical power of the present experiments to detect effects congruent with those previously reported.

Parenthetically, either of two models would be consistent with the failure to find visual field $x$ value interactions. First, it could be that, in normal behavior, the left hemisphere effectively bears sole responsibility for word recognition by virtue of more efficient or even exclusive processing. Alternatively, it might be that both hemispheres participate and that the hemispheric lexicons are equivalent in concreteness and imageability values, but that the left hemisphere is somewhat more efficient in word recognition. Both models would produce a general right-field superiority failing to interact with attribute values. Although the present results cannot distinguish between them, it is worth noting that split-brain data support the lexical competency of the right hemisphere (Searleman, 1977).

Nothing in these results bears on the third challenge to Paivio's position, the logical and empirical dissociability of concreteness and imageability. Nevertheless, in the absence of evidence indicating that separate psychological dimensions underlie these word attributes, dissociability remains only a potential challenge. It is possible, of course, that any such evidence would require only a modest modification of dual-processing theory, incorporating separate "concreteness" and "imageability" referential memories.

Finally, although the combined results of these experiments and the literature reviewed in the introduction do support those aspects of Paivio's theory dealing with "verbal" and "imagery" codes, it should be noted that other aspects of the theory have been criticized. Specifically, Paivio pointed to another type of "referential" memory for words (other than imagery), which he termed a "verbal associative" process and which was considered to be indexed by "meaningfulness," a quantified index of the number of verbal associations to a word. By the logic of Paivio's distinction between "representational" and "referential" memories, word recognition should no more depend on meaningfulness than on imageability/concreteness, yet some researchers have found that it does, including Paivio himself (e.g., Johnson, Frincke, \& Martin, 1961; Paivio \& O'Neill, 1970). In addition, a number of recent studies have uncovered effects of a priming word (which may be subthreshold and therefore is not recognized) on RTs to a related word (e.g., Carr, McCauley, Sperber, \& Parmelee, 1982; Humphreys, Evett, \& Taylor, 1982; Schvaneveldt \& McDonald, 1981; Underwood \& Thwaites, 1982), a result that also suggests an influence of verbal associative meaning on word recognition. To his credit, Paivio noted the discrepancy between the earlier results and his theory, pointing out the challenge that the discrepancy raises in proposing a mechanism by which such effects can occur.
The answer to the challenge proposed by one current school of thought is that mental processes are best likened to a "cascade" of activation rather than to discrete stages of processing (McClelland, 1979). By this view, serial processes are deemphasized in favor of parallel processes whose results emerge at varying points in time. Applied to the present problem, this view predicts that all sources of word memory should influence word recognition, including "verbal associative meaning," since associations would be activated by a word regardless of overt recognition. Therefore, a cascade of processes can account for the effects of meaningfulness and semantically related primes.

The cascade model, however, has difficulty accounting for the opposite finding, which is that imageability and concreteness do not affect word recognition. If one type of associative meaning (meaningfulness) affects recognition, then another type should as well (imageability/ concreteness). We accordingly have an interesting quandary: Continuous-processing models like the cascade model handle the effect of meaningfulness but not the null effect of imageability/concreteness, whereas discreteprocessing models like that of Paivio handle the null effect of imageability/concreteness but not the effect of meaningfulness. How can the results be reconciled?

One possibility that can be suggested here is that verbal memory codes may be more highly related among themselves than they are to imagery, which is outside the verbal system. .This higher relatedness then results in a greater tendency for activation to cascade within the system. By this means, a word's semantic associates can be activated and assist in the recognition of the word itself, whereas associated imagery is outside the system and therefore is either not affected by the cascade or else fails to cascade its own output to recognition processes. According to this view, Paivio was correct in pointing to familiar/frequency, meaningfulness, and imageability/concreteness as indexes of three different aspects of word memory, and was also correct in labeling the former aspect as representational and the latter two aspects as associative, but he may have been incorrect in assuming that all associative memories must be inoperative in the near-threshold recognition of words. On the other hand, this view would also hold that the cascade model may be correct when applied to highly interrelated systems of processes, but has not taken sufficient notice of isolable systems between which the transmission of information may be more discrete than continuous (see Miller, 1983).

\section{REFERENCE NOTE}

1. Paivio, A. Imagery and familiarity ratings for 2448 words: Unpublished norms. Unpublished manuscript, Department of Psychology, University of Western Ontario.

\section{RETERENCES}

Binketr, P. Measures of laterality and theories of hemispheric processes. Neuropsychologia, 1977, 15, 693-696. 
Boles, D. B. Hemispheric interaction in visual field asymmetry. Cortex, 1983, 19, 99-114.

Boles, D. B., Rogers, S., \& WyMer, W. Age of acquisition and visual field asymmetry in word recognition. Perception \& Psychophysics, 1982, 32, 486-490.

Borkowski, J. G., Spreen, O., \& Stutz, J. Z. Ear preference and abstractness in dichotic listening. Psychonomic Science, $1965,3,547-548$.

Bradshaw, J. L., \& Gates, E. A. Visual field differences in verbal tasks: Effects of task familiarity and sex of subject. Brain and Language, 1978, 5, 166-187.

Bradshaw, J. L., Nettleton, N. C., \& Taylor, M. J. Right hemisphere language and cognitive deficit in sinistrals? Neuropsychologia, 1981, 19, 113-132.

Bryden, M. P. Laterality: Functional asymmetry in the intact brain. New York: Academic Press, 1982.

Bryden, M. P., \& Allard, F. Dichotic listening and the development of linguistic processes. In M. Kinsbourne (Ed.), Asymmetrical function of the brain. Cambridge: Cambridge University Press, 1978.

Caplan, D., Holmes, J. M., \& Marshall, J. C. Word classes and hemispheric specialization. Neuropsychologia, 1974, 12, 331-337.

Carr, T. H., McCauley, C., Sperber, R. D., \& Parmelee, C. M. Words, pictures, and priming: On semantic activation, conscious identification, and the automaticity of information processing. Journal of Experimental Psychology: Human Perception and Performance, 1982, 8, 757-777.

Colbourn, C. J. Can laterality be measured? Neuropsychologia, 1978, 16, 283-289.

DAY, J. Right-hemisphere language processing in normal righthanders. Journal of Experimental Psychology: Human Perception and Performance, 1977, 3, 518-528.

DAY, J. Visual half-field word recognition as a function of syntactic class and imageability. Neuropsychologia, 1979, 17 , 515-519.

Dixon, W. J., \& Mas8ey, F. J. Introduction to statistical analysis. New York: McGraw-Hill, 1969.

ELL18, H. D., \& SHePHerD, J. W. Recognition of abstract and concrete words presented in left and right visual fields. Journal of Experimental Psychology, 1974, 103, 1035-1036.

Elman, J. L., TAkahashi, K., \& TohsakU, Y. Lateral asymmetries for the identification of concrete and abstract Kanji. Neuropsychologia, 1981, 19, 407-412.

Gilhooly, K, J., \& HAY, D. Imagery, concreteness, age-ofacquisition, familiarity, and meaningfulness values for 205 fiveletter words having single-solution anagrams. Behavior Research Methods \& Instrumentation, 1977, 9, 12-17.

HatTA, T. Lateral recognition of abstract and concrete Kanji in Japanese. Perceptual and Motor Skills, 1977, 45, 731-734.

HaYnes, W. O., \& Moone, W. H. Sentence imagery and recall: An electroencephalographic evaluation of hemispheric processing in males and females. Cortex, 1981, 17, 49-62.

HaYs, W. L. Statistics for the social sciences. New York: Holt, Rinehart \& Winston, 1973.

Hines, D. Recognition of verbs, abstract nouns, and concrete nouns from the left and right visual half-fields. Neuropsychologia, 1976, 14, 211-216.

Howes, D. H., \& Solomon, R. L. Visual duration threshold as a function of word-probability. Journal of Experimental Psy. chology, 1951, 41, 401-410.

HuMphreYs, G. W., EveTt, L. J., \& TaYlon, D. E. Automatic phonological priming in visual word recognition. Memory \& Cognition, 1982, 10, 576-590.

Johnson, R. C., Frincke, G., M Martin, L. Meaningfulness, frequency, and affective character of words as related to visual duration thresholds. Canadian Journal of Psychology, 1961, 15, 199-204.

Jones, D., \& SPREen, $O$. Dichotic listening by retarded children: The effects of ear order and abstractness. Child Development, $1967,38,101-105$.
Kelly, R. R., \& Onton, K. D. Dichotic perception of wordpairs with mixed image values. Neuropsychologia, 1979, 17, 363-371.

Lambert, A. J., \& Benumont, J. G. On Kelly and Orton's 'Dichotic perception of word pairs with mixed image values.' Neuropsychologia, 1982, 20, 209-210.

LEIBER, L. Lexical decisions in the right and left cerebral hemispheres. Brain and Language, 1976, 3, 443-450.

Mackavey, W., Curcio, F., \& Rosen, J. Tachistoscopic word recognition performance under conditions of simultaneous presentation. Neuropsychologia, 1975, 13, 27-33.

Marcel, A. J., \& Patterson, K. E. Word recognition and production: Reciprocity in clinical and normal studies. In J. Requin (Ed.), Attention and performance VII. Hillsdale, N.J: Erlbaum, 1978.

Marghall, J. C., Caplan, D., \& Holmes, J. M. The measure of laterality. Neuropsychologia, 1975, 13, 315-321.

McClelland, J. L. On the time relations of mental processes: An examination of systems of processes in cascade. Psychological Review, 1979, 86, 287.330.

McFarland, K., McFarland, M. L., Bain, J. D., Ashton, R. Ear differences of abstract and concrete word recognition. Neuropsychologia, 1978, 16, 555-561.

McGinnies, E., Comer, P. B., \& Lacey, O. L. Visual-recognition thresholds as a function of word length and word frequency. Journal of Experimental Psychology, 1952, 44, 65-69.

Mitler, J. Can response preparation begin before stimulus recognition finishes? Journal of Experimental Psychology: Human Perception and Performance, 1983, 9, 161-182.

Orenstein, H. B., \& Meiohan, W. B. Recognition of bilaterally presented words varying in concreteness and frequency: Lateral dominance or sequential processing? Bulletin of the Psychonomic Society, 1976, 7, 179-180.

Paivio, A. Imagery and verbal processes. New York: Holt, Rinehart \& Winston, 1971.

Paivio, A., \& O'Neill, B. J. Visual recognition thresholds and dimensions of word meaning. Perception \& Psychophysics, 1970, 8, 273-275.

Paivio, A., Yuilie, J. C., \& Madiann, S. A. Concreteness, imagery, and meaningfulness values for 925 nouns. Journal of Experimental Psychology Monograph, 1968, 76(1, Pt. 2).

Posnen, M. I., \& McLeOD, P. Information processing modelsIn search of elementary operations. Annual Review of Psychol. ogy, 1982, 33, 477-514.

Richardson, J. T. E. The effects of stimulus attributes upon latency of word recognition. British Journal of Psychology, 1976, 67, 315-325.

RIEGEL, K. F., \& RIEGEL, R. M. Prediction of word-recognition thresholds on the basis of stimulus-parameters. Language and Speech, 1961, 4, 157-170.

Rosenthal, R. Combining results of independent studies. Psychological Bulletin, 1978, 85, 185-193.

Rosenthal, R., \& Rubin, D. B. Comparing significance levels of independent studies. Psychological Bulletin, 1979, 86, $1165-1168$.

Rubenete in, H., Garfield, L., \& Mlllikan, J. A. Homographic entries in the internal lexicon. Journal of Verbal Learning and Verbal Behavior, 1970, 9, 487-492.

Saffran, E. M., Bocyo, L. C., Schwartz, M. F., \& Marin, O. S. M. Does deep dyslexia reflect right-hemisphere reading? In M. Coltheart, K. Patterson, \& J. C. Marshall (Eds.), Deep dyslexia. London: Routledge \& Kegan Paul, 1980.

Schmuller, J., \& Goodman, R. Bilateral tachistoscopic perception, handedness, and laterality. Brain and Language, 1979, 8, $81-91$.

Schvanteved, R. W., \& McDonald, J. E. Semantic context and the encoding of words: Evidence for two modes of stimulus analysis. Journal of Experimental Psychology: Human Perception and Performance, 1981, 7, 673-687.

Searleman, A. A review of right hemisphere linguistic capabilities. Psychological Bulletin, 1977, 84, 503-528. 
Shanon, B. Lateralization effects in response to words and nonwords. Cortex, 1979, 15, 541-549.

Solomon, R. L., \& Howes, D. H. Word frequency, personal values, and visual duration thresholds. Psychological Review, $1951,58,256-270$.

Spreen, O., Bonkowski, J. G., \& Benton, A. L. Auditory word recognition as a function of meaningfulness, abstractness, and phonetic structure. Journal of Verbal Learning and Verbal Behavior, 1967, 6, 101-104.

Suarshita, M. Mental association in the minor hemisphere of a commissurotomy patient. Neuropsychologia, 1978, 16, 229-232.

Taylor, J. A., Rosenfeldt, D. C., \& Schulz, R. W. The relationship between word frequency and perceptibility with a forced- choice technique. Journal of Abnormal and Social Psychology, $1961,62,491-496$.

Unde RWOod, G., \& Thwartes, S. Automatic phonological coding of unattended printed words. Memory \& Cognition, 1982, 10, 434-442.

Winnick, W. A., \& Kresset, K. Tachistoscopic recognition thresholds, paired-associate learning, and free recall as a function of abstractness-concreteness and word frequency. Journal of Experimental Psychology, 1965, 70, 163-168.

(Manuscript received February 18, 1982; revision accepted for publication August 25, 1983.) 